\title{
Characterization of angiotensin-converting enzyme inhibitory activity of fermented milk produced by Lactobacillus helveticus
}

\author{
Yongfu Chen, ${ }^{*}$ Changkun Li, ${ }^{*}$ Jiangang Xue, ${ }^{*}$ Lai-yu Kwok, ${ }^{*}$ Jie Yang, ${ }^{*}$ Heping Zhang, ${ }^{*} \dagger$ and Bilige Menghe* \\ *Key Laboratory of Dairy Biotechnology and Engineering, Ministry of Education P.R.C. Inner Mongolia Agricultural University, \\ Synergetic Innovation Center of Food Safety and Nutrition, Huhhot 010018, P. R. China. \\ †Synergetic Innovation Center of Food Safety and Nutrition, Jiang Nan University, Wuxi, Jiang Su 214122, P. R. China
}

\section{ABSTRACT}

Hypertension affects up to $30 \%$ of the adult population in most countries. It is a known risk factor for cardiovascular diseases, including coronary heart disease, peripheral artery disease, and stroke. Owing to the increased health awareness of consumers, the application of angiotensin-converting enzyme (ACE)inhibitory peptides produced by Lactobacillus helveticus to prevent or control high blood pressure has drawn wide attention. A total of $59 \mathrm{~L}$. helveticus strains were isolated from traditional fermented dairy products and the ACE-inhibitory activity of the fermented milks produced with the isolated microorganisms was assayed. The ACE-inhibitory activity of 38 L. helveticus strains was more than 50\%, and 3 strains (IMAU80872, IMAU80852, and IMAU80851) expressing the highest ACE-inhibitory activity were selected for further studies. Particularly, the gastrointestinal protease tolerance and thermostability of the ACE-inhibitory activity in the fermented milks were assessed. Based on these 2 criteria, IMAU80872 was found to be superior over the other 2 strains. Furthermore, IMAU80872 exhibited a high in vitro ACE-inhibitory activity at the following fermentation conditions: fermentation temperature at $40^{\circ} \mathrm{C}$, inoculation concentration of $1 \times 10^{6} \mathrm{cfu} / \mathrm{mL}$, and fermentation for $18 \mathrm{~h}$. Finally, by using ultraperformance liquid chromatography coupled with electrospray ionization quadrupole time-of-flight tandem mass spectrometry analysis, we observed changes of the metabolome along the milk fermentation process of IMAU80872. Furthermore, 6 peptides were identified, which might have ACE-inhibitory activity. In conclusion, we identified a novel ACE-inhibitory L. helveticus strain suitable for the production of fermented milk or other functional dairy products.

Received January 26,

Accepted March 15, 2015.

${ }^{1}$ Corresponding author: menghe@sjtu.edu.cn
Key words: Lactobacillus helveticus, angiotensinconverting enzyme, fermented milk, peptide

\section{INTRODUCTION}

It has been reported that, as of $2000,>25 \%$ of the population worldwide (approximately 1 billion) had been affected by hypertension, and this figure is predicted to increase to 1.56 billion by 2025 (Kearney et al., 2005). The rennin-angiotensin-aldosterone system is a key factor in the maintenance of arterial blood pressure. In this system, angiotensin-converting enzyme (ACE; EC 3.4.15.1) cleaves the dipeptide portion of angiotensin I from the C-terminal and produces a potent vasopressor angiotensin II, which induces the release of aldosterone that causes the retention of sodium ions by the kidney and elevates the blood volume, thus increasing the blood pressure (Skeggs et al., 1956). Moreover, ACE also catalyzes the inactivation of bradykinin, which has an important vasodilation activity, leading to an elevated blood pressure. Therefore, ACE plays an important role in the regulation of arterial blood pressure, and inhibiting this enzyme can generate an antihypertensive effect. In fact, ACE-inhibitors are an excellent physiological target for clinical hypertensive treatment due to their involvement in the reninangiotensin system and kinin-nitric oxide system.

Currently available ACE-inhibitors are synthetic pharmacological drugs and their use in healthy or low-risk populations is not advisable because of their adverse effects, such as dry cough, skin rashes, and angioneurotic edema. Thus, developing safe and natural ACE-inhibitors is necessary for future treatment and prevention of hypertension (Jao et al., 2012). These peptides have already been isolated from a variety of fermented dairy products, including cheese, yogurt, and fermented bovine milk (Donkor, 2007; Hartmann and Meisel, 2007; Qian et al., 2011). The fermented milk proteins, including both caseins and whey proteins, are rich sources of ACE-inhibitory peptides, as these peptides are embedded within their primary structures. They can be released by enzymatic hydrolysis during 
gastrointestinal digestion, food processing (FitzGerald et al., 2004), and microbial fermentation (Hajirostamloo, 2010).

Lactobacillus helveticus is a probiotic bacterium that is known to produce abundant intracellular proteolytic enzymes, including cell-envelope proteinases, endopeptidases, aminopeptidases, and the X-prolyl dipeptidyl aminopeptidase (PepX; Haandrikman et al., 1991; Exterkate, 1995). Some of these enzymes are capable of releasing ACE-inhibitory peptides into fermented milk drinks. Nakamura et al. (1995) reported the hypotensive effect of the tripeptides Val-Pro-Pro (VPP) and Ile-Pro-Pro (IPP), which were produced from milk fermentation with a combination of $L$. helveticus and Saccharomyces cerevisiae. Gobbetti et al. (2000) isolated the ACE-inhibitory polypeptides LNVPGEIVE and NVPGEIVE from yogurt-type products fermented with Lactobacillus delbreukii spp. bulgaricus and Lactococcus lactis spp. cremoris.

One key factor that may affect the in vivo efficiency of ACE-inhibitory peptides is their bioavailability. To effectively administer the ACE-inhibitory peptides orally to hypertensive patients, it is important to ensure that these peptides pass through the digestive tract and are absorbed through the intestinal epithelium (Jao et al., 2012). Digestion of proteins and peptides starts in the stomach by the action of pepsin at acidic $\mathrm{pH}$, and then the polypeptides are further truncated by the pancreatic proteases, trypsin, a-chymotrypsin, elastase, and carboxypeptidases A and B at a more alkaline $\mathrm{pH}$ (Jao et al., 2012). The gastric and intestinal enzymes confer preferential proteolytic activity to the substrates. For example, pepsin can damage leucine residue and $\mathrm{C}$ terminal aromatic AA, whereas trypsin preferentially attacks positively charged C-terminal AA (such as Arg and Lys) and chymotrypsin targets at the aromatic or hydrophobic AA (such as Tyr, Phe, and Trp; Neurath, 1957; Auffret and Ryle, 1979). The combined proteolytic activity results in the release of potential bioactive peptides, which may exert a direct function at the gastrointestinal tract. Moreover, some common food-processing treatments also affect the efficiency of ACE-inhibitory peptide. For example, heat treatment is conventionally used to kill microorganisms and inactivate undesirable enzyme activity to extend the shelf life of food. However, heat treatment will also damage the nutrients and functional bioactive substances in the food products to some extent. Hannu et al. (1998) reported that the functional properties of peptides in the food matrix are highly influenced by their molecular structure, interactions with other components and the conditions of food processing. In particular, heat treatment of ACE-inhibitory peptides in fermented milk may destroy their hypotensive function.
Owing to the unique genetic makeup of each bacterial starter strain, the fermentation process and the final composition of the metabolites in the fermented products may vary. Metabolomics is an approach that has emerged over the last decade and it provides interesting potential to be applied in food science and microbiology (Fiehn, 2002). The metabolomic approach can either be targeted to specific compounds or metabolic pathways or untargeted for generating global chemical fingerprints of the samples. In either case, this approach aids in depicting and quantifying metabolites that are present within the food matrix. Specifically, it may also help to identify the hypertensive components of dairy products fermented by L. helveticus.

Thus, the first objective of the current study was to screen the fermented milk products of 59 previously isolated food-originated L. helveticus for potential strains with high ACE-inhibitory activity. Second, as the ACE-inhibitory peptides have to retain their activity after the food fermentation and ripening processes, as well as surviving the gastrointestinal digestive enzymes, the resistances of the ACE-inhibitory activity of the selected strains against heat treatment and gastrointestinal transit were evaluated. Third, the fermentation conditions (fermentation temperature, initial inoculum density, and fermentation time) required for producing fermented milk with a high ACE-inhibitory activity were assessed. Finally, the change in metabolomic profile during milk fermentation of the strain IMAU 80872 was monitored by ultra-performance liquid chromatography coupled with electrospray ionization quadrupole time-of-flight tandem mass spectrometry (UPLC-ESI$\mathrm{QTOF} / \mathrm{MS})$.

\section{MATERIALS AND METHODS}

\section{Original Sources of L. helveticus Strains}

In our previous work (Zhang et al., 2012), 59 strains of $L$. helveticus were isolated from different traditional fermented dairy products ( 20 from Kurut, a traditional fermented yak milk; 23 from Qula, a traditional fermented yak milk crude cheese; 7 from fresh yak milk; 9 from yogurt whey) collected in Gansu Province of China. These strains were identified as L. helveticus by a combination of traditional physiological and biochemical identification methods together with $16 \mathrm{~S}$ rRNA gene sequence analysis as published in a previous report (Bao et al., 2012).

\section{Bacterial Stocks and Preparation of Fermented Milks}

The 59 strains of L. helveticus were preserved as freeze-dried powder at the Lactic Acid Bacteria Culture 
Collection (Inner Mongolia Agricultural University, China). The L. helveticus strains were first activated in reconstituted skim milk at $37^{\circ} \mathrm{C}$ overnight, followed by a second passage in MRS broth at $37^{\circ} \mathrm{C}$ overnight. They were then used as starter cultures in the fermentation experiments. The reconstituted milk was prepared by suspending $11 \%$ (wt/wt) skim milk powder (NZMP Ltd., Wellington, New Zealand) in sterilized distilled water at $95^{\circ} \mathrm{C}$ for $10 \mathrm{~min}$.

Fermented milks were made in culture flasks by inoculating with seed cultures of $L$. helveticus strains at a concentration of $5 \times 10^{6} \mathrm{cfu} / \mathrm{mL}$. Inoculated milk cultures were incubated at $37^{\circ} \mathrm{C}$ for $24 \mathrm{~h}$. The titratable acidity $\left(\mathbf{T A},{ }^{\circ} \mathrm{T}\right)$ was determined by titration with $\mathrm{NaOH}$ using phenolphthalein as the indicator (National Standards of the People's Republic of China, 2010) and $\mathrm{pH}$ value of fermented milk samples was determined according to Method No. 947.05 of the Association of Official Analytical Chemists (AOAC, 1990). The bacterial growth was determined by spectrophotometric measurement of optical density at $600 \mathrm{~nm}$ (UV-1700, Shimadzu, Kyoto, Japan). The finished fermented milks were centrifuged at $6,000 \times g$ for $10 \mathrm{~min}$ at $4^{\circ} \mathrm{C}$ for supernatant collection, and the collected supernatants were stored at $-20^{\circ} \mathrm{C}$ until further use in the determination of ACE-inhibitory activity, free amino nitrogen (FAN; Church et al., 1983), and VPP and IPP contents.

\section{Determination of In Vitro ACE-Inhibitory Activity}

The ACE-inhibitory activity was measured using the HPLC method described by Chen et al. (2010) with some modifications. The substrate, hippuryl-L-histidylL-leucine (HHL), and rabbit lung powder containing ACE were obtained from Sigma Chemical Co. (St. Louis, MO). Both HHL and ACE were separately dissolved in $100 \mathrm{~m} M$ Na-borate buffer (pH 8.3) containing $300 \mathrm{~m} M \mathrm{NaCl}$. The assay was performed by incubating a mixture of $50 \mu \mathrm{L}$ of milk supernatant sample and 50 $\mu \mathrm{L}$ of HHL $(10 \mathrm{mM})$ solution at $37^{\circ} \mathrm{C}$ for $2 \mathrm{~min}$. Then, $50 \mu \mathrm{L}$ of $\mathrm{ACE}(0.010 \mathrm{U} / \mathrm{mL})$ solution was then added and the mixture was further incubated at $37^{\circ} \mathrm{C}$ for 30 min. The reaction was stopped by heating the mixture in $85^{\circ} \mathrm{C}$ water bath for 10 min to inactivate the enzyme. Afterward, $150 \mu \mathrm{L}$ of deionized water was added before $20 \mu \mathrm{L}$ of this solution was directly injected onto a Zorbax $\mathrm{C}_{18}$ column $(4.6 \times 250 \mathrm{~mm}$, particle size 5 $\mu \mathrm{m}$, Agilent, Santa Clara, CA) to separate the product, hippuric acid, from HHL. The column was eluted with $75 \%$ acetonitrile in water ( $\mathrm{vol} / \mathrm{vol}$ ) containing $0.1 \%$ trifluoroacetic acid at a flow rate at $1.5 \mathrm{~mL} / \mathrm{min}$ using a pump; the eluent was monitored at $228 \mathrm{~nm}$. The column temperature was controlled at $30^{\circ} \mathrm{C}$.
The ACE-inhibition activity was calculated from the following equation:

$$
\begin{gathered}
\text { ACE-inhibition activity }= \\
{[(\mathrm{Cc}-\mathrm{Cs}) /(\mathrm{Cc}-\mathrm{Cb})] \times 100 \%,}
\end{gathered}
$$

where $\mathrm{Cc}, \mathrm{Cb}$, and $\mathrm{Cs}$ were the concentrations of hippuric acid without the tested sample (control $=\mathrm{Cc}$ ), without ACE (blank = Cb), and with both $\mathrm{ACE}$ and the tested sample ( sample $=\mathrm{Cs}$ ).

\section{Characterization of Milk ACE-Inhibitors by Protease Digestion}

To characterize the nature and the resistance of ACEinhibitory materials in the fermented milks to gastrointestinal proteases, samples were digested alone either with pepsin (1:10,000, Sigma Chemical Co.) or trypsin (1:250, Sigma Chemical Co.), or sequentially with pepsin followed by trypsinase (Figure 1). Enzymatically digested samples were then assayed for ACE-inhibitory activity as described above. The procedures for enzyme digestion were modified from Chen et al. (2010).

\section{Thermostability of ACE-Inhibitory Materials in L. helveticus-Fermented Milk}

The ACE-inhibitory fermented milks produced by $L$. helveticus were treated with 3 different heating processes, namely $63^{\circ} \mathrm{C}$ for $30 \mathrm{~min}, 75^{\circ} \mathrm{C}$ for $25 \mathrm{~s}$, and $85^{\circ} \mathrm{C}$ for $20 \mathrm{~s}$. After the samples were immediately cooled down to $4^{\circ} \mathrm{C}$ in an ice bath, their $\mathrm{pH}$ was adjusted to 8.3. The ACE-inhibitory activity was measured.

\section{Influence of Fermentation Temperature, Inoculum Concentration, and Fermentation Time on ACE- Inhibitory Activity of L. helveticus-Fermented Milks}

Based on the ACE-inhibitory activity stability after protease digestion and heat treatment, selected strains were tested in milk fermentation experiments to determine how the fermentation temperature, inoculum concentration, and fermentation time affected the level of ACE-inhibitory activity during L. helveticus-fermented milk production. To assess the effect of fermentation temperature, the fermented milk was made in the flask culture by inoculating with $2 \%$ (vol/vol, $5 \times 10^{6} \mathrm{cfu} /$ $\mathrm{mL}$ ) of $L$. helveticus seed culture. The culture was incubated at 33,37 , and $40^{\circ} \mathrm{C}$ until the content reached $\mathrm{pH}$ 4.5. The ACE-inhibitory activity of the fermented milks was then measured.

To test the effect of inoculum concentration, the fermented milk was made in the flask culture inoculated 


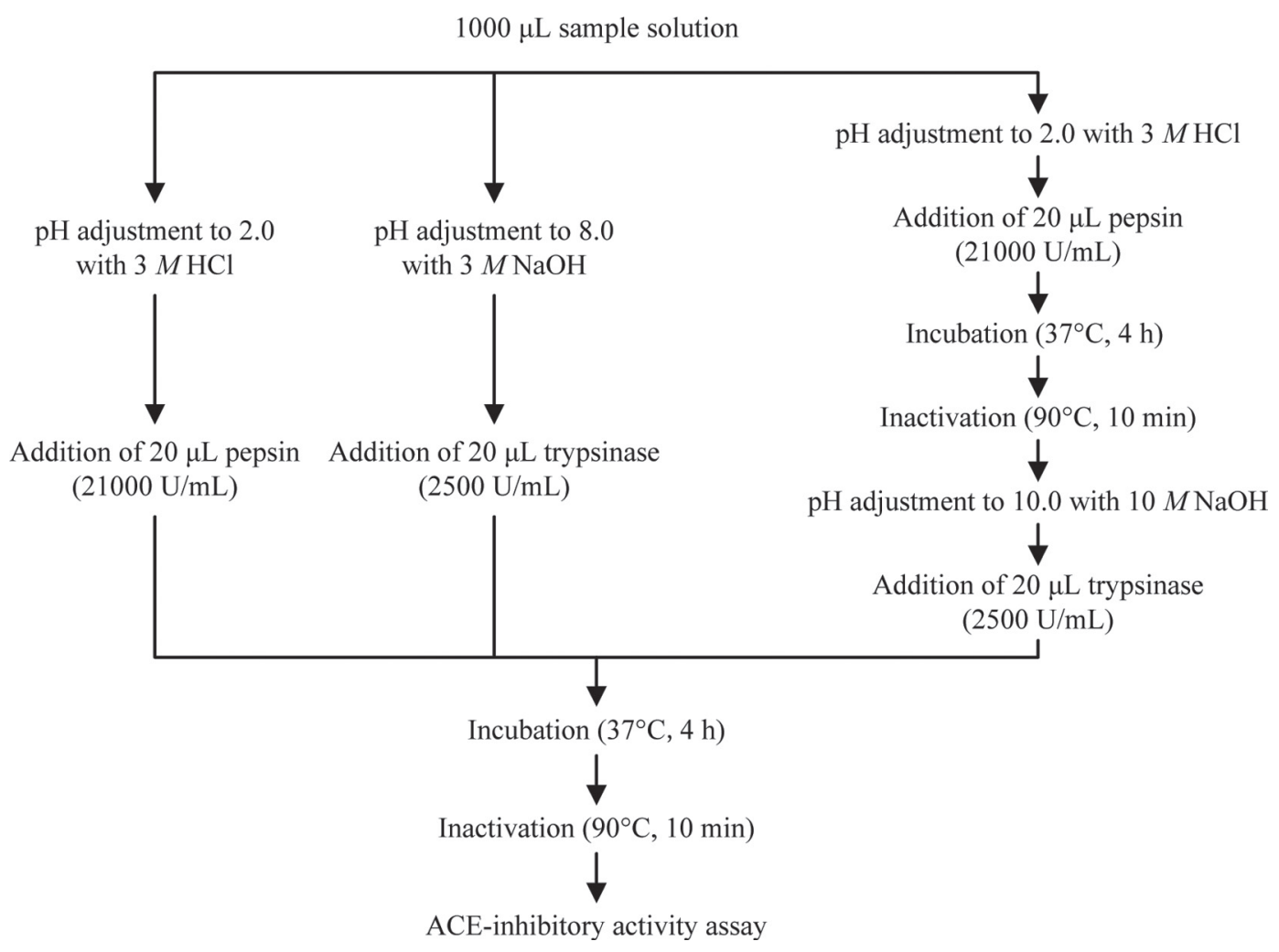

Figure 1. The procedures of fermented milk digestion by gastrointestinal proteases. ACE = angiotensin-converting enzyme.

with different concentrations $\left(1 \times 10^{6}, 5 \times 10^{6}, 1 \times 10^{7}\right.$, or $5 \times 10^{7} \mathrm{cfu} / \mathrm{mL}$ ) of L. helveticus seed culture. Inoculated cultures were fermented at $40^{\circ} \mathrm{C}$ until $\mathrm{pH}$ 4.5. The ACE-inhibitory activity, FAN, TA ( $\left.{ }^{\circ} \mathrm{T}\right)$, VPP, and IPP contents of the fermented milks were then measured.

To optimize the fermentation time, the milk was fermented with seed culture concentration of $1 \times 10^{6} \mathrm{cfu} /$ $\mathrm{mL}$ at $40^{\circ} \mathrm{C}$. These conditions were chosen based on the results from the optimization of inoculum density and fermentation temperature. The $\mathrm{pH}$ value, TA, FAN content, optical density at $600 \mathrm{~nm}$, ACE-inhibitory activity, VPP, and IPP contents were determined at $0,2,4,6,8,10,12,18,24,30,36,42$, and $48 \mathrm{~h}$ upon fermentation.

\section{Quantification of VPP and IPP by Ultra-Performance Liquid Chromatography-Tandem Mass Spectrometry}

Separations of VPP and IPP in the supernatants from the fermented milk samples were performed on an ultraperformance liquid chromatography (UPLC) system (Waters, Milford, MA) connected to a quadrupole time of flight instrument (Q-Tof, Waters, Manchester, UK). The UPLC system was equipped with a binary gradient pumping system, a photo diode array detector set at
$220 \mathrm{~nm}$, and an automatic injector (Waters). The 2.1 $\times 100 \mathrm{~mm}$ BEH-C $\mathrm{C}_{18}$ column (Waters) was used in these experiments. The injection volume was $4 \mu \mathrm{L}$. Solvent A was a mixture of water-formic acid (100:0.1, vol/ vol) and solvent B contained acetonitrile-formic acid (100:0.1, vol/vol). Peptides were eluted with a linear gradient of solvent B in A going from 5 to $30 \%$ over 5 min at a flow rate of $0.4 \mathrm{~mL} / \mathrm{min}$.

Data were acquired from $\mathrm{m} / z 100$ to 700 using a desolvation temperature of $350^{\circ} \mathrm{C}$, source temperature of $100^{\circ} \mathrm{C}$, cone voltage of $30 \mathrm{~V}$, and collision energy of $6 \mathrm{eV}$. The nitrogen desolvation and nebulizer gas flow rates were set to 600 and $50 \mathrm{~L} / \mathrm{h}$, respectively. The mass spectrometer was calibrated across the $\mathrm{m} / \mathrm{z}$ range of 100 to 1,500 using a solution of sodium formate. Data were centroided during acquisition using an external reference comprising a $2-\mathrm{ng} / \mathrm{mL}$ solution of Leu-encephalin infused at $10 \mu \mathrm{L} / \mathrm{min}$, generating an $[\mathrm{M}+\mathrm{H}]$ ion at $m / z 556.2771$.

The peptides IPP and VPP were prepared by a conventional Fmoc solid-phase synthesis method with a 431A peptide synthesizer (Applied Biosystems Inc., Uberlingen, Germany). The purity of the synthesized peptides was verified by analytical HPLC coupled to MS. 


\section{Metabolic Profiling by UPLC-ESI-QTOF/MS Analysis}

The metabolites of L. helveticus IMAU80872 over $48 \mathrm{~h}$ of milk fermentation were analyzed by UPLCESI-QTOF/MS (Waters) according to the method of Zhang et al. (2013). In short, an aliquot of $5 \mu \mathrm{L}$ of sample solution was injected onto an Acquity UPLC BEH C18 column $(100 \mathrm{~mm} \times 2.1 \mathrm{~mm}, 1.7 \mu \mathrm{m}$, Waters $)$ at $40^{\circ} \mathrm{C}$ with the flow rate of $0.4 \mathrm{~mL} / \mathrm{min}$. The optimal mobile phase consisted of a linear gradient system of (A) $0.1 \%$ formic acid in water and (B) $0.1 \%$ formic acid in acetonitrile; $2 \% \mathrm{~B}$ was used from 0 to $0.5 \mathrm{~min}$; from 0.5 to 24 min, B was increased from 2 to $100 \%$ linearly; from 24 to 27.5 min, $100 \%$ B was constant; then, B was decreased to $2 \%$ and kept for $2 \mathrm{~min}$. The column temperature was controlled at $30^{\circ} \mathrm{C}$.

Mass spectrometry was operated by electrospray ionization in the positive ionization mode. The eluent was subject to analysis by a high-definition mass spectrometer (Waters) with analysis conditions as follows: the source temperature was $100^{\circ} \mathrm{C}$, desolvation gas temperature was $350^{\circ} \mathrm{C}$, cone gas flow was $1 \mathrm{~L} / \mathrm{h}$, desolvation gas flow was $800 \mathrm{~L} / \mathrm{h}$, the capillary voltage was 3.2 $\mathrm{kV}$, the sampling cone voltage was $32 \mathrm{~V}$, microchannel plate voltage was $2,300 \mathrm{~V}$, and extraction cone voltage was $3.0 \mathrm{~V}$. The mass spectrometry data were collected in the range of 100 to $1,000(\mathrm{~m} / \mathrm{z})$.

\section{Processing of Metabolomics Data and Identification of Differential Components}

Data from UPLC/ESI-QTOF/MS measurement were imported into the MarkerLynx Application Manager (V4.1, Waters) software for peak detection and alignment. The intensity of each ion was normalized with respect to the total ion count to generate a data matrix that consisted of the retention time, $m / z$ value, and the normalized peak area $(10,000)$. The multivariate data matrix was analyzed by EZinfo software 2.8 (Waters). All the variables were mean-centered and Pareto scaled before principal component analysis (PCA) and partial least square-discriminant analysis (PLS-DA). A PCA allows visualization of variation of metabolic profiles of samples collected at different fermentation time points, whereas PLS-DA calculates models that differentiate between sample groups.

The identification of differentiated chemical components along the fermentation process was based on the the PLS-DA loading plot and the S-plot of variable importance projection (VIP) confidence interval (VIP $>1$ ). Differentiated fermentation metabolites were chosen based on their contribution to the variation and correlation within the data set. The MassFragment Application Manager (Waters) was used to facilitate the
MS/MS fragment ion analysis process by chemically intelligent peak-matching algorithms. The identities of the specific metabolites were confirmed by comparison of their mass spectra and chromatographic retention times. The ion spectra of metabolites of interest were matched with the structure message of metabolites acquired from open biochemical databases, such as HMDB (http://www.hmdb.ca/), METLIIN (http:// metlin.scripps.edu/), MassBank (http://www.massbank.jp/), and KEGG (http://www.genome.jp/kegg/).

\section{Statistical Analysis}

All experiments were performed in triplicate. Statistically significant differences between sample groups were evaluated with ANOVA. $P$-values of less than 0.05 were considered statistically significant differences between sample groups. Analysis of variance and correlation analysis were performed with SAS software (SAS version 9.00, SAS Institute, Inc., Cary, NC).

\section{RESULTS AND DISCUSSION}

During the fermentation of milk, the major milk proteins are degraded into peptides due to the action of indigenous milk enzymes (mainly plasmin), added coagulants, and microbial enzymes originated from the starter and nonstarter lactic acid bacteria $(\mathbf{L A B})$. Among the LAB, the species L. helveticus has the highest extracellular proteinase activity and, thus, the highest ability to release bioactive peptides, including the hypotensive, ones to the fermented milk (Yamamoto et al., 1994). The principal aim of our paper was to screen 59 candidate $L$. helveticus strains and identify potential hypotensive strain that is suitable to be applied in milk fermentation.

\section{Selection of L. helveticus Strains Based on Fermentation Characteristics and ACE-Inhibitory Activity}

The $\mathrm{pH}$ value, FAN, TA, and ACE-inhibitory activity of $59 \mathrm{~L}$. helveticus fermented milks (after $24 \mathrm{~h}$ of fermentation) are presented in Supplemental Table S1 (http://dx.doi.org/10.3168/jds.2015-9382). To assess the acidification capacity of these strains, 2 parameters, including $\mathrm{pH}$ and $\mathrm{TA}$, were measured. The $\mathrm{pH}$ value and TA ranged from 3.35 to 5.22 and 49.00 to $240.42^{\circ} \mathrm{T}$, respectively, suggesting that the acidification capacity varied widely among strains. The growth of the strains was reflected by the absorbance at $600 \mathrm{~nm}$, ranging from 0.01 to 0.68 , whereas the FAN content fell between 1.65 to $10.5 \mathrm{nmol} / \mathrm{L}$. Thirty-eight out of the 59 tested strains showed a relatively high ACE-inhibitory activity 
Table 1. Physical parameters of fermented milks produced by 3 Lactobacillus helveticus strains with highest angiotensin-converting enzyme (ACE)-inhibitory activity (mean $\pm \mathrm{SD})^{1}$

\begin{tabular}{lccccc}
\hline Strain No. & $\mathrm{pH}$ value & $\mathrm{TA}\left({ }^{\circ} \mathrm{T}\right)$ & $\mathrm{OD}_{600}$ & $\begin{array}{c}\text { FAN } \\
(\mathrm{mmol} / \mathrm{L})\end{array}$ & $\mathrm{ACEI}(\%)$ \\
\hline IMAU80851 & $3.51 \pm 0.01$ & $178.46 \pm 4.85$ & $0.205 \pm 0.35$ & $8.88 \pm 0.14$ & $81.71 \pm 0.00$ \\
IMAU80852 & $3.36 \pm 0.00$ & $240.42 \pm 2.43$ & $0.337 \pm 0.06$ & $8.90 \pm 0.31$ & $81.68 \pm 0.01$ \\
IMAU80872 & $3.37 \pm 0.01$ & $225.93 \pm 1.35$ & $0.226 \pm 0.03$ & $7.22 \pm 0.17$ & $76.64 \pm 0.04$ \\
\hline \multicolumn{1}{l}{${ }^{1} \mathrm{TA}=$ titratable acidity; $\mathrm{OD}_{600}=$ absorbance at $600 \mathrm{~nm}$. FAN = free amino nitrogen; ACEI = ACE-inhibitory. }
\end{tabular}

of over $50 \%$. Interestingly, the ACE-inhibitory activity was significantly $(P<0.01)$ and positively correlated to the acidity and FAN in the fermented milk (Figure 2 ). This may reflect that the ACE-inhibitory activity was produced during the process of fermentation and microbial metabolism, in particular the proteolytic action on the milk proteins.

As all these strains were originally isolated from traditionally fermented foods, our results so far have shown 2 important points. First, based on the assessed fermentation properties, namely acidification capacity, bacterial growth, and FAN, it can be concluded that there was a large intraspecies variation in these properties. Thus, a screen approach is necessary for selecting appropriate strains suitable for food industrial application. Second, all these strains originated from traditionally fermented products, suggesting that these products are good sources for isolating hypotensive $L$. helveticus strains. Furthermore, potential exists to use these strains in dairy industry to generate products of additional health benefit (Muguerza et al., 2006). Based on the ACE-inhibitory activity, 3 strains (IMAU80872, IMAU80852, and IMAU80851) showing the highest ACE-inhibitory activity $(76.64 \pm 0.04,81.68 \pm 0.01$, and $81.71 \pm 0.00 \%$, respectively) were chosen for further characterization (Table 1).

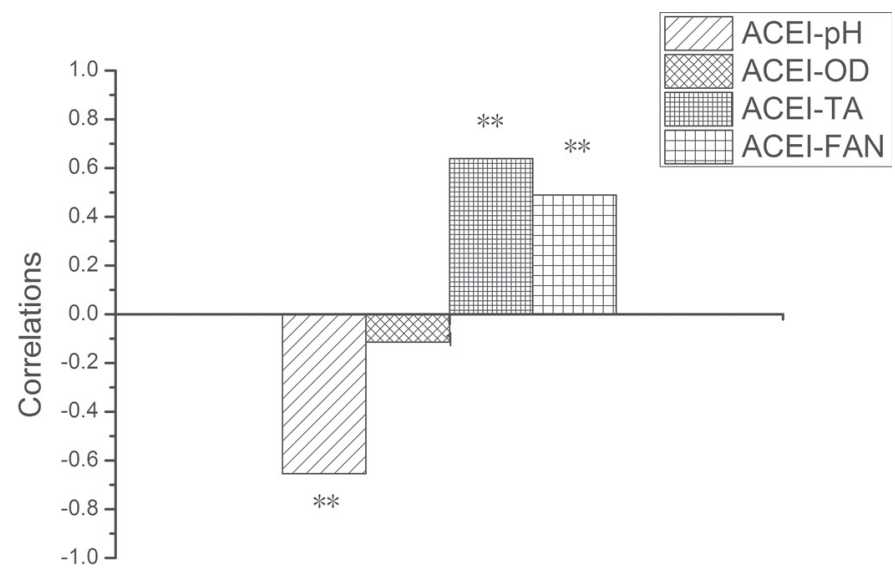

Figure 2. Correlation between angiotensin-converting enzyme (ACE)-inhibitory activity and 4 physical parameters of Lactobacillus helveticus fermented milk. ${ }^{* *} P<0.01$.

\section{ACE-Inhibitory Activity of Milk After Digestion by Protease}

Approximately $90 \%$ of the absorption of peptides in the gastrointestinal tract takes place in the region of the small intestine (Regazzo, 2010). However, it is known that the in vitro ACE-inhibitory activity and in vivo hypotensive effect may not be directly correlated. One of the reasons is the gastrointestinal resistance of these peptides; of equal importance is whether the peptides require an additional proteolytic activation step to fully release its bioactivity. The ACE-inhibitory peptides from different sources have been isolated, including yogurt, cheese, ovalbumin, koumiss, and meat (Pihlanto-Leppälä et al. 1998; Foltz et al., 2007; Chen et al., 2010; Darewicz et al., 2014). It was found that the activity of ACE-inhibitory peptides may be higher or lower after proteolytic digestion. Thus, to investigate the effect of gastrointestinal proteases on the ACEinhibitory activity, fermented milk samples produced by IMAU80872, IMAU80852, and IMAU80851 were digested with pepsin, trypsinase, or pepsin followed by trypsinase, and the ACE-inhibitory activity of untreated and treated samples were compared (Figure 3). It was found that the ACE-inhibitory activity of these 3 L. helveticus-fermented milks significantly increased $(P<0.05)$ after digestion by proteases, regardless of a single or sequential protease treatment, suggesting that the ACE-inhibitory materials were resistant to gastrointestinal proteases. The sequential pepsintrypsinase treatment of IMAU80872-, IMAU80852-, and IMAU80851-fermented milks increased the ACEinhibitory activity from $76.84 \pm 0.29,76.84 \pm 0.29$, and $79.58 \pm 0.31 \%$ to $89.68 \pm 0.19,87.27 \pm 0.34$, and $89.34 \pm 0.27 \%$, respectively $(P<0.05$, comparing the untreated and treatment samples in each case). Our results also show that a proteolytic activation step was indeed required to release the ACE-inhibitory activity fully.

According to Fujita et al. (2000), ACE-inhibitory peptides in vitro can be classified into 3 groups: (1) true inhibitor type, with $50 \%$ inhibition values of peptides that are not affected by preincubation with ACE or gastrointestinal proteases; (2) substrate type, with 


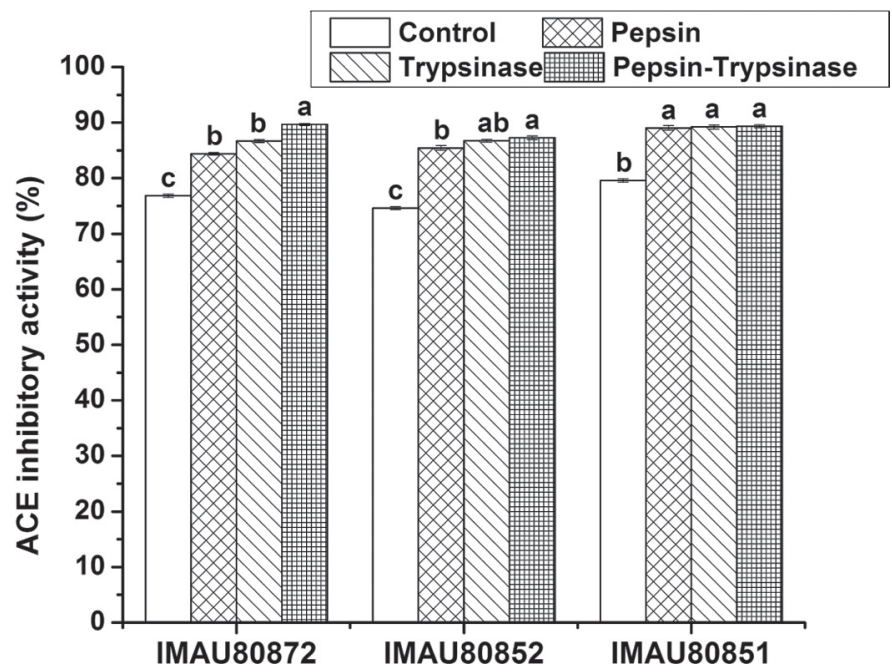

Figure 3. Angiotensin-converting enzyme (ACE)-inhibitory activity of fermented milks after gastrointestinal protease digestion. Statistical differences between groups are represented by different letters $(\mathrm{a}-\mathrm{c} ; P<0.05)$. Error bars indicate SD.

peptides that are converted to true inhibitors by ACE or gastrointestinal proteases, resulting in peptides with weaker activity; and (3) prodrug type, with peptides that are converted to true inhibitors by ACE or gastrointestinal proteases. Our results suggest that the ACEinhibitors in the fermented milks produced by these 3 strains were of the prodrug type or a mixture of the prodrug and the true inhibitor types.

Similar to our study, Matsui et al. (1999) reported that the ACE-inhibitory activity of the small peptide (isoleucine-valine-tyrosine) isolated from wheat germ increased by $27 \%$ after enzyme hydrolysis by a mixture of pepsin, trypsin, and chymotrypsin. Qureshi et al. (2013) reported a significant increase in the ACEinhibitory activity of Gamalost and Norvegia cheeses $(P<0.05)$ upon digestion by human gastrointestinal and duodenal juices (healthy volunteers), as the cheese was enzymatically digested to produce several active $\beta$-CN-derived peptides and AA.

\section{Thermostability of ACE-Inhibitory Fermented Milk by L. helveticus}

During modern dairy processing, yogurts are subjected to various kinds of heat treatments. Therefore, to ensure the heat stability of ACE-inhibitory activity, the fermented milks of IMAU80872, IMAU80852, and IMAU80851 were heat treated at different conditions simulating to industrial dairy pasteurization processes, and the effect of such processes on the ACE-inhibitory activity was monitored (Figure 4). Only the ACEinhibitory activity of IMAU80872-fermented milk was not significantly affected by any of the tested heating process $(P>0.05)$. The ACE-inhibitory activities of IMAU80852- and IMAU80851-fermented milks were significantly reduced after heat treatments at $75^{\circ} \mathrm{C}$ for $25 \mathrm{~s}$ and $80^{\circ} \mathrm{C}$ for $20 \mathrm{~s}$, respectively $(P<0.05)$. These results suggest that the ACE-inhibitory activity of IMAU80872-fermented milk had the highest heat stability. Other heat-stable ACE-inhibitory materials have previously been reported. For example, no significant change was noted in the ACE-inhibitory activities of peptides separated from tuna and soy even after $100^{\circ} \mathrm{C}$ heat treatment $(P>0.05$; Wu and Ding, 2002; Hwang, 2010). Owing to the high heat stability of the ACE-inhibitory activity of IMAU80872-fermented milk and its great potential for industrial use, we further established the optimum fermentation conditions (including the fermentation temperature, time, and initial inoculum density) of this strain in relation to its ACE-inhibitory activity.

\section{Influence of Fermentation Temperature, Inoculum Density, and Fermentation Time on ACE-Inhibitory Activity of L. helveticus IMAU80872-Fermented Milk}

Lactobacillus helveticus IMAU80872 was allowed to ferment at 33,37 , and $40^{\circ} \mathrm{C}$. No significant difference was found in the resultant ACE-inhibitory activity in the fermented milks $(77.30 \pm 0.13,79.65 \pm 0.20$, and $81.19 \pm 0.19 \%$, respectively; $P>0.05$ ), although an increasing trend of ACE-inhibitory activity was observed with an increase in the fermentation temperature (Figure 5). Similar results were reported by Otte

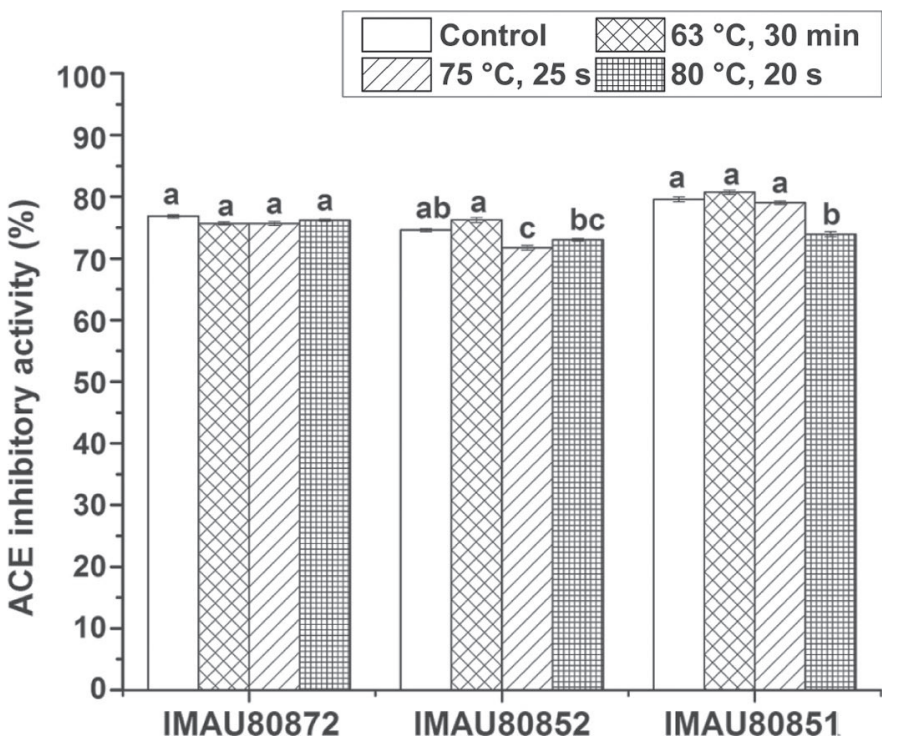

Figure 4. Effect of different heat treatments on angiotensin-converting enzyme (ACE)-inhibitory activity of fermented milk. Statistical differences between groups are represented by different letters $(\mathrm{a}-\mathrm{c} ; P$ $<0.05)$. Error bars indicate SD. 


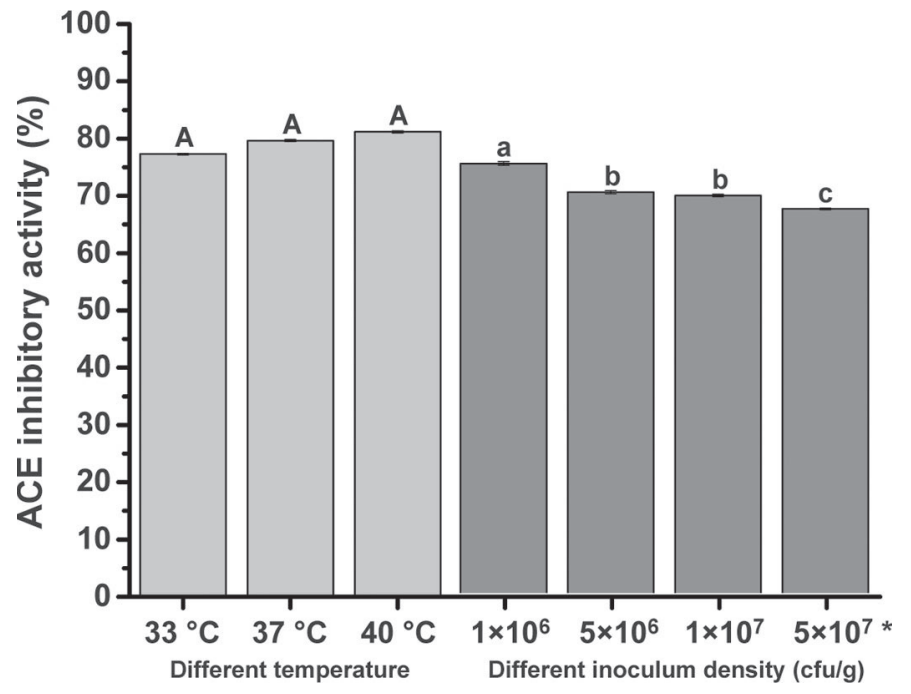

Figure 5. Effect of fermentation temperature and inoculum density on the angiotensin-converting enzyme (ACE)-inhibitory activity of Lactobacillus helveticus IMAU80872 fermented milks. Significant differences in the ACE-inhibitory activity between fermented milks produced with different temperature and inoculum densities are represented by different letters $(\mathrm{A}-\mathrm{C}$ and $\mathrm{a}-\mathrm{c}$, respectively; $P<0.05$ ). Error bars indicate SD.

et al. (2011) using the strains L. helveticus MI1198 and CHCC4080. The slight increase of ACE-inhibitory activity may be related to a higher efficiency of the proteolytic enzyme in releasing bioactive peptides. Pan and Guo (2010) studied the correlation between the fermentation temperature of $L$. helveticus LB10 and its cell wall proteinase, aminopeptidase, prolyl dipeptidyl aminopeptidase enzymes, as well as the ACE-inhibition rate, and found that the cell wall proteinase and ACEinhibitory activity, but not other enzymes, were closely related.

The effect of different initial inoculum density of $L$. helveticus IMAU80872 on the fermented milk ACEinhibitory activity was also tested. Interestingly, the fermented milk ACE-inhibition rate was related to the initial inoculum density, as the fermented milk produced with the inoculation of $1 \times 10^{6} \mathrm{cfu} / \mathrm{g}$ had significantly higher ACE-inhibitory activity than those made with higher starting $L$. helveticus concentrations $(74.97$ \pm 0.33 vs. $69.95 \pm 0.29,69.40 \pm 0.23$, and $67.04 \pm$ $0.15 \%$ corresponding to higher initial inoculum levels; $P<0.05$; Figure 5). This phenomenon was probably related to the growth conditions of the starter bacteria, as a lower initial bacterial density might have offered a less competitive environment in terms of nutrients and metabolites for bioactive peptide synthesis. As the inoculum concentration increased, a rapid growth might have caused an excessive acid production, which in turn suppressed the proteolytic activity that was required for the generation of bioactive peptides.
Along the milk fermentation of L. helveticus IMAU80872, various parameters changed (Figure 6). In the logarithmic phase (6-10 h; Figure 6), bacterial cells grew exponentially. Most likely, during this time, bacterial cell wall proteinases were produced, accumulated, and in turn enhanced protein hydrolysis (essentially casein), leading to the release of peptides and free AA. The global increase in free AA in the medium fulfilled the AA requirements for the growth of the bacteria (Juillard et al., 1995). Thus, a rapid increase in FAN and fermented milk peptides was observed, and this was followed by an increase in ACE-inhibitory activity (Figure 6). Our results are in line with those reported in Pan and Guo (2010) that L. helveticus LB10-produced ACE-inhibitory peptides and bacterial cell wall proteinases during the logarithmic and stationary phases. With the extension of the stationary phase $(10-30 \mathrm{~h})$, more organic acids accumulated, which caused the continuous drop of the milk $\mathrm{pH}$ value. This then decreased the bacterial activity and slowed down the elevation of ACE-inhibitory activity and release of FAN (Figure 6). However, the FAN content turned to a downward trend after $18 \mathrm{~h}$ of fermentation, which may be due to the deprivation of nutrients available to the microbes. Otte et al. (2011) found that there was no absolute correlation between LAB fermented milk ACE-inhibition rate with the bacterial intracellular enzyme, PepX. In our study, the absorbance of fermented milk declined after $30 \mathrm{~h}$ of fermentation, suggesting that the L. helveticus IMAU80872 cells started to lyse. In that case, the bacterial intracellular enzymes would also be released. However, the ACE-inhibitory activity of the fermented milk remained stable, indicating that such activity was not directly relating to the bacterial intracellular enzymes, confirming the results of Otte et al. (2011).

The changes of VPP and IPP concentrations and the ACE-inhibitory activity during milk fermentation of $L$. helveticus IMAU80872 is shown in Figure 6. Interestingly, the ACE-inhibitory activity of the fermented milk rapidly increased after around $10 \mathrm{~h}$ of fermentation, although the VPP and IPP contents were almost undetectable. The fact that the ACE-inhibitory activity did not correlate well with the appearance of VPP and IPP and that the VPP and IPP peptides appeared relatively late may suggest that the ACE-inhibitory activity was largely not based on the VPP and IPP peptides. Moreover, even when more VPP and IPP were detectable after $12 \mathrm{~h}$ of fermentation, no change was observed in the fermented milk ACE-inhibitory activity, which further supports our speculation that the ACE-inhibitory activity was likely conferred by mechanisms other than VPP and IPP peptides. Similarly, Bütikofer et al. (2007) also found poor correlation between the sum of the 2 tripeptides, VPP and IPP, and 


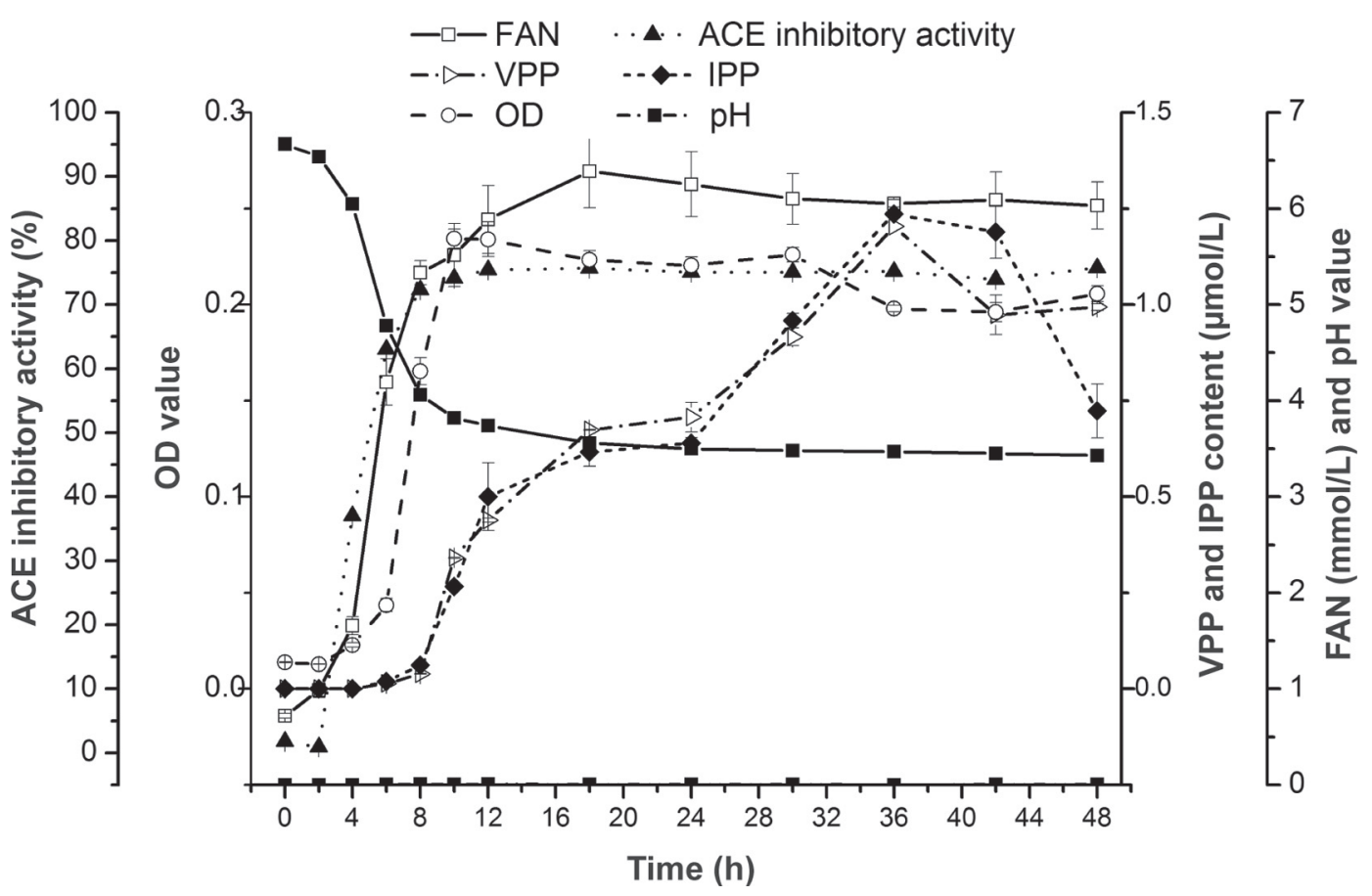

Figure 6. Changes of angiotensin-converting enzyme (ACE)-inhibitory activity, free amino nitrogen (FAN), Val-Pro-Pro (VPP), and IlePro-Pro (IPP) concentrations, absorbance at $600 \mathrm{~nm}\left(\mathrm{OD}_{600}\right)$, and $\mathrm{pH}$ during Lactobacillus helveticus IMAU80872 milk fermentation. Error bars indicate SD.

the $50 \%$ inhibition values of ACE-inhibitory activity in soft cheese samples. Finally, after 36 h of fermentation, the fermented milk VPP and IPP concentrations were slightly reduced, which might be due to the depletion of both nutrients and casein substrate in the fermented milk. Thus, the release of VPP and IPP naturally reduced and the bacteria might have started to use other nutrient sources in the environment including these readily digestible peptides.

\section{Identification of Differential Metabolites During Milk Fermentation}

To identify which metabolites contributed to the ACE-inhibitory activity in the fermented milk sample, we monitored the change in metabolic profile of fermented milks of IMAU80872 at different time points of fermentation by UPLC/ESI-QTOF/MS analysis. A total of 11,365 types of metabolites (each signal was represented by a different $\mathrm{m} / \mathrm{z}$ detected at the same retention time) were collected over the $48 \mathrm{~h}$. A PCA was performed based on the whole data set, including triplicate samples taken at each time point (Figure 7). The first 2 principal components accounted for 76 and $8 \%$ of the variation, respectively. Samples from 0 to 12 $\mathrm{h}$ showed a clear pattern of shift from the left to the right side of the PCA score plot, suggesting gradual changes of the chemical composition during the milk fermentation. Meanwhile, samples collected beyond 18 $\mathrm{h}$ of fermentation clustered closely, indicating that no significant chemical changes in the metabolic profile occurred after this time point, which might correspond to the stationary phase of the bacteria growth (Figure 6).

Due to the results of the PCA, further analysis at 2 and $12 \mathrm{~h}$ of fermentation was performed with PLSDA (S-plot is shown in Figure 8). Each dot represents a different type of metabolite on the S-plot, with the $\mathrm{x}$ - and $\mathrm{y}$-axis representing contribution coefficient and correlation, respectively. Metabolites far from the cross section of $\mathrm{x}$ - and $\mathrm{y}$-axes were the more relevant ions for discrimination between groups. Based on cutoff of confidence level or VIP $>1,6$ differential metabolites showing significant difference between these 2 fermentation time points could be identified. Interestingly, all 6 metabolites were peptide in nature (Table 2). The identities of these peptides were confirmed by cross checking their MS/MS data at public chemical databanks, including HMDB, METLIIN, MassBank, and KEGG databases. Some of these peptides, including ALPM, VAGTWY, and IPI, have previously been reported to show ACE-inhibitory activity (references in Table 2), whereas the ACE-inhibitory capacity of the other 3 identified peptides remains to be evaluated in future work. 


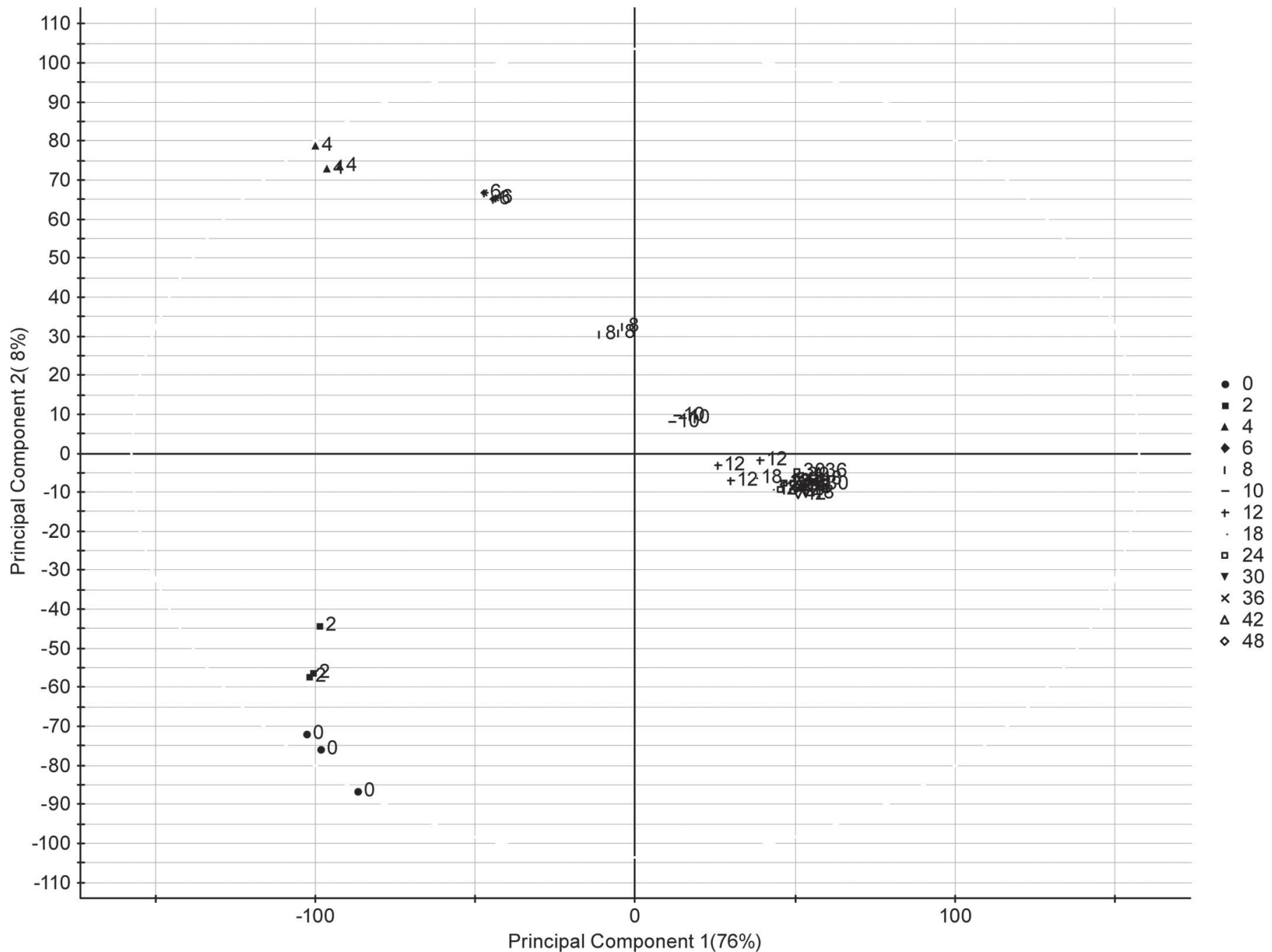

Figure 7. Principal component analysis score plot showing the dynamics of metabolic profiles during fermentation. Triplicate samples were taken at each time point. Symbols of different shapes correspond to the fermentation time in hours.

\section{CONCLUSIONS}

Our study preliminarily assessed the ACE-inhibitory activity of 59 L. helveticus-fermented milks. Thirty-eight of the tested fermented milks had an ACE-inhibitory activity of more than 50\%. The strains IMAU80872, IMAU80852, and IMAU80851 possessed the highest ACE-inhibitory activity. Subsequent assessments found

Table 2. Differential peptides identified at 2 and $12 \mathrm{~h}$ of IMAU80872 milk fermentation

\begin{tabular}{llccll}
\hline $\begin{array}{l}\text { Peptide } \\
\text { No. }\end{array}$ & $\begin{array}{l}\text { Peptide } \\
\text { sequence }\end{array}$ & $\begin{array}{c}\text { Measured } \\
\text { mass }\end{array}$ & $m / z$ & Source of peptide & $\begin{array}{l}\text { Angiotensin-converting } \\
\text { enzyme-inhibitory activity } \\
\text { reported previously }\end{array}$ \\
\hline 1 & LKP & 365.5042 & 33.8677 & $\beta$-LG f(61-63) & - \\
2 & ALPM & 430.6 & 8.4736 & $\beta$-LG f(158-161) & Mullally et al. (1997) \\
3 & PGPIHD & 634.8022 & 14.086 & Unidentified & - \\
4 & VAGTWY & 695.8347 & 19.623 & $\beta-$ LG f(31-36) & Pihlanto-Leppälä et al. (1998) \\
5 & DN & 247.2045 & 22.5127 & Unidentified & Chiba and Yoshikawa (1991) \\
6 & IPI & 341.5 & 27.0878 & k-CN f(25-28) & Chiba \\
\hline
\end{tabular}




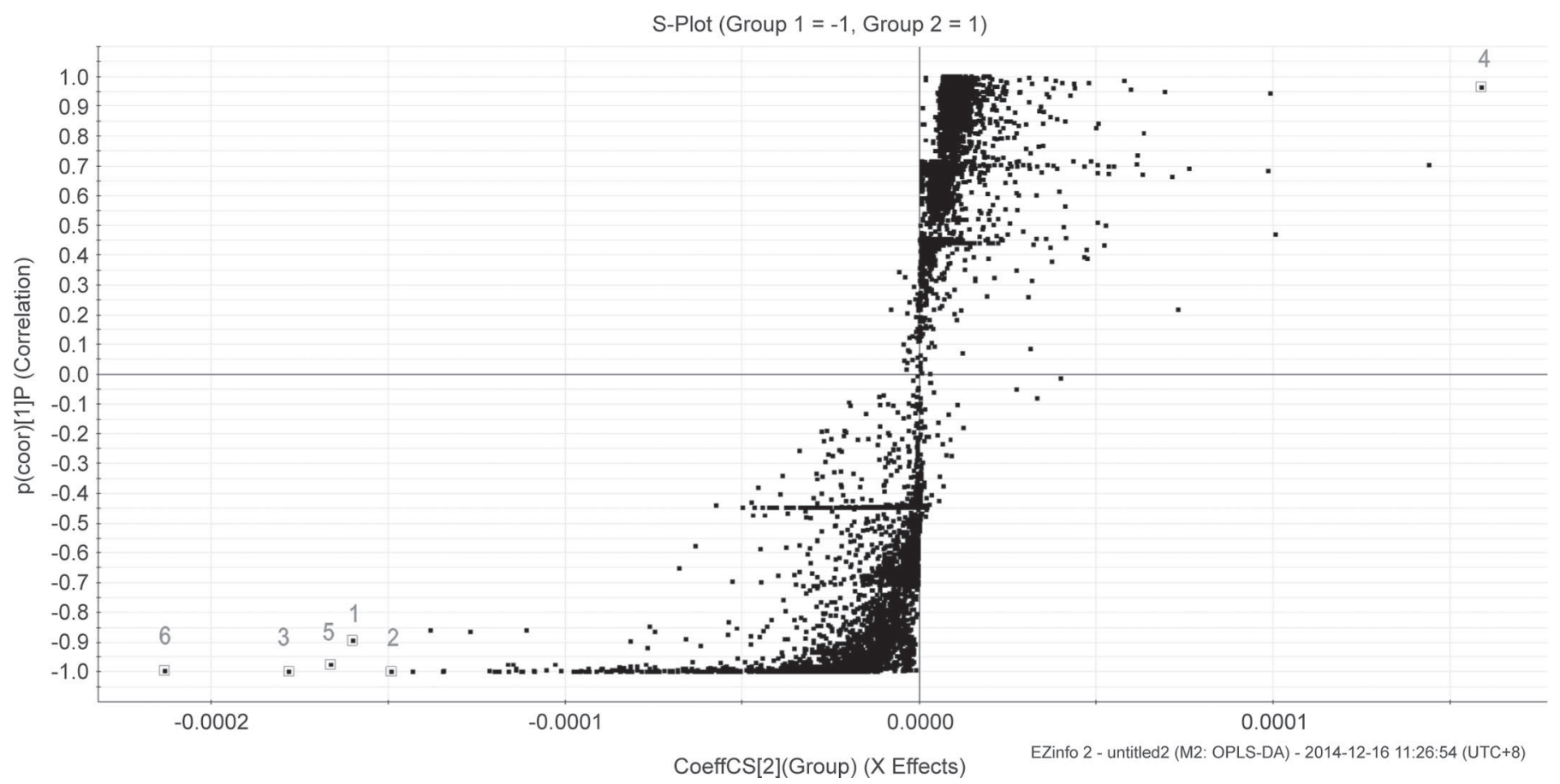

Figure 8. S-plot of partial least square-discriminant analysis of metabolomes after 2 and $12 \mathrm{~h}$ of fermentation. X- and y-axes correspond to the contribution coefficient and the correlation, respectively. Each dot represents 1 type of metabolite. The 6 differential metabolites showing significant difference (variable importance projection $>1$ ) between the 2 time points marked.

that IMAU80872 was superior to the other 2 strains, as the fermented milk produced by IMAU80872 was the most resistant to both protease and heat treatments. The fermentation for $18 \mathrm{~h}$ at $40^{\circ} \mathrm{C}$ with the initial inoculum density of $1 \times 10^{6} \mathrm{cfu} / \mathrm{g}$ were the optimal conditions for IMAU80872 to produce fermented milks with high ACE-inhibitory activities. Finally, we identified 6 differential peptides that were significantly enriched after milk fermentation of $12 \mathrm{~h}$ by IMAU 80872 . To conclude, our study identified a novel bioactive ACE-inhibitory L. helveticus strain that is suitable to be used in antihypertensive fermented yogurt or other functional dairy products.

\section{ACKNOWLEDGMENTS}

This research was supported by the National Natural Science Foundation of China (Beijing, China; Grant No. 31101315), the Hi-Tech Research and Development Program of China (Beijing, China; Grant No. 2011AA100902), the Special Fund for Agro-scientific Research in the Public Interest (Beijing, China; Grant No. 201303085), and the Program for Young Talents of Science and Technology in Universities of Inner Mongolia Autonomous Region (Hohhot, China; Grant No. NJYT-13-B11, 20120317).

\section{REFERENCES}

AOAC. 1990. Official Methods of Analysis. 15th ed. Assoc. Off. Anal. Chem. Arlington, VA.

Auffret, C. A., and A. P. Ryle. 1979. The catalytic activity of pig pepsin C towards small synthetic substrates. Biochem. J. 179:239246

Bao, Q., W. J. Liu, J. Yu, W. H. Wang, M. J. Qing, X. Chen, F. Wang, J. C. Zhang, W. Y. Zhang, J. M. Qiao, T. S. Sun, and H. P. Zhang. 2012. Isolation and identification of cultivable lactic acid bacteria in traditional yak milk products of Gansu Province in China. J. Gen. Appl. Microbiol. 58:95-105.

Bütikofer, U., J. Meyer, R. Sieber, and D. Wechsler. 2007. Quantification of the angiotensin-converting enzyme-inhibiting tripeptides Val-Pro-Pro and Ile-Pro-Pro in hard, semi-hard and soft cheeses. Int. Dairy J. 17:968-975.

Chen, Y., Z. Wang, X. Chen, Y. Liu, H. Zhang, and T. Sun. 2010 Indentification of angiotensin I-converting enzyme inhibitory peptides from koumiss, a traditional fermented mare's milk. J. Dairy Sci. 93:884-892.

Chiba, H., and M. Yoshikawa. 1991. Bioactive peptides derived from food proteins. Kagaku To Seibutsu 29:454-458.

Church, F. C., H. E. Swaisgood, D. H. Porter, and G. L. Catignani. 1983. Spectrophotometric assay using phthaldialdehyde for determination of proteolysis in milk and isolated milk proteins. J. Dairy Sci. 66:1219-1227.

Darewicz, M., J. Borawska, G. E. Vegarud, P. Minkiewicz, and A. Iwaniak. 2014. Angiotensin I-converting enzyme (ACE) inhibitory activity and ACE inhibitory peptides of salmon (Salmo salar) protein hydrolysates obtained by human and porcine gastrointestinal enzymes. Int. J. Mol. Sci. 15:14077-14101.

Donkor, O. N. 2007. Influence of probiotic organisms on release of bioactive compounds in yoghurt and soy yoghurt. Ph.D Thesis, Victoria University, Melbourne, Australia. 
Exterkate, F. A. 1995. The lactococcal cell envelope proteinases: Differences, calcium-binding effects and role in cheese ripening. Int. Dairy J. 5:995-1018.

Fiehn, O. 2002. Metabolomics - The link between genotypes and phenotypes. Plant Mol. Biol. 48:155-171.

FitzGerald, R. J., B. A. Murray, and D. J. Walsh. 2004. Hypotensive peptides from milk proteins. J. Nutr. 134:980S-988S.

Foltz, M., E. E. Meynen, V. Bianco, C. van Platerink, T. M. M. G. Koning, and J. Kloek. 2007. Angiotensin converting enzyme inhibitory peptides from a lactotripeptide-enriched milk beverage are absorbed intact into the circulation. J. Nutr. 137:953-958.

Fujita, H., K. Eiichiyokoyama, and M. Yoshikawa. 2000. Classification and antihypertensive activity of angiotensin I-converting enzyme inhibitory peptides derived from food proteins. J. Food Sci. 65:564-569.

Gobbetti, M., P. Ferranti, E. Smacchi, F. Goffredi, and F. Addeo. 2000. Production of angiotensin-I-converting enzyme inhibitory peptides in fermented milks started by Lactobacillus delbrueckii ssp. bulgaricus SS1 and Lactococcus lactis ssp. cremoris FT4. Appl. Environ. Microbiol. 66:3898-3904.

Haandrikman, A. J., R. Meesters, H. Laan, W. N. Konings, J. Kok, and G. Venema. 1991. Processing of the lactococcal extracellular serine proteinase. Appl. Environ. Microbiol. 57:1899-1904.

Hajirostamloo, B. 2010. Bioactive component in milk and dairy product. World Acad. Sci. Eng. Technol. 48:137-141.

Hannu, K., P. Anne, R. Pirjo, and T. Tuomo. 1998. Impact of processing on bioactive proteins and peptides. Trends Food Sci. Technol. 9:307-319.

Hartmann, R., and H. Meisel. 2007. Food-derived peptides with biological activity: From research to food applications. Curr. Opin. Biotechnol. 18:163-169.

Hwang, J. S. 2010. Impact of processing on stability of angiotensin Iconverting enzyme (ACE) inhibitory peptides obtained from tuna cooking juice. Food Res. Int. 43:902-906.

Jao, C. L., S. L. Huang, and K. C. Hsu. 2012. Angiotensin I-converting enzyme inhibitory peptides: Inhibition mode, bioavailability, and antihypertensive effects. BioMedicine 2:130-136.

Juillard, V., D. Lebars, E. R. S. Kunji, W. N. Konings, J. C. Gripon, and J. Richard. 1995. Oligopeptides are the main source of nitrogen for Lactococcus lactis during growth in milk. Appl. Environ. Microbiol. 61:3024-3030.

Kearney, P. M., M. Whelton, K. Reynolds, P. Muntner, P. K. Whelton, and J. He. 2005. Global burden of hypertension: Analysis of worldwide data. Lancet 365:217-223.

Matsui, T., C. H. Li, and Y. Osajima. 1999. Preparation and characterization of novel bioactive peptides responsible for angiotensin I-converting enzyme inhibition from wheat germ. J. Pept. Sci. 5:289-297.

Muguerza, B., M. Ramos, E. Sánchez, M. A. Manso, M. Miguel, A. Aleixandre, M. A. Delgado, and I. Recio. 2006. Antihypertensive activity of milk fermented by Enterococcus faecalis strains isolated from raw milk. Int. Dairy J. 16:61-69.

Mullally, M. M., H. Meisel, and R. J. FitzGerald. 1997. Identification of a novel angiotensin-I-converting enzyme inhibitory peptide cor- responding to a tryptic digest of bovine $\beta$-lactoglobulin. FEBS Lett. 402:99-101.

Nakamura, Y., N. Yamamoto, K. Sakai, A. Okubo, S. Yamazaki, and T. Takano. 1995. Purification and characterization of angiotensin I-converting enzyme inhibitors from sour milk. J. Dairy Sci. 78:777-783.

National Standards of the People's Republic of China. 2010. Method for Analysis of Hygienic Standard of Milk and Milk Products. Bulletin 5413.34. CNS, Beijing, China.

Neurath, H. 1957. Some considerations of the multiple specificity of proteolytic enzymes. Ann. N. Y. Acad. Sci. 68:11-23.

Otte, J., T. Lenhard, B. Flambard, and K. I. Sørensen. 2011. Influence of fermentation temperature and autolysis on ACE-inhibitory activity and peptide profiles of milk fermented by selected strains of Lactobacillus helveticus and Lactococcus lactis. Int. Dairy J. $21: 229-238$

Pan, D., and Y. Guo. 2010. Optimization of sour milk fermentation for the production of ACE-inhibitory peptides and purification of a novel peptide from whey protein hydrolysate. Int. Dairy J. 20:472-479.

Pihlanto-Leppälä, A., T. Rokka, and H. Korhonen. 1998. AngiotensinI-converting enzyme inhibitory peptides derived from bovine milk proteins. Int. Dairy J. 8:325-331.

Qian, B., M. Xing, L. Cui, Y. Deng, Y. Xu, M. Huang, and S. Zhang. 2011. Antioxidant, antihypertensive, and immunomodulatory activities of peptide fractions from fermented skim milk with Lactobacillus delbrueckii ssp. bulgaricus LB340. J. Dairy Res. 78:72-79.

Qureshi, T. M., G. E. Vegarud, R. K. Abrahamsen, and S. Skeie. 2013. Angiotensin-I-converting enzyme-inhibitory activity of the Norwegian autochthonous cheeses Gamalost and Norvegia after in vitro human gastrointestinal digestion. J. Dairy Sci. 96:838-853.

Regazzo, D. 2010. Bioactive peptides from milk proteins: Focusing on peptides displaying immunomodulatory activity. $\mathrm{PhD}$ Thesis. Univ. of Padova, Italy. Accessed Dec. 10, 2014. http://paduaresearch. cab.unipd.it/2590/1/TESIregazzo.pdf.

Skeggs, L. T., J. E. Kahn, and N. P. Shumway. 1956. The preparation and function of the angiotensin-converting enzyme. J. Exp. Med. 103:295-299.

Wu, J. P., and X. L. Ding. 2002. Characterization of inhibition and stability of soy-protein-derived angiotensin-I-converting enzyme inhibitory peptides. Food Res. Int. 35:367-375.

Yamamoto, N., A. Akino, and T. Takano. 1994. Antihypertensive effect of different kinds of fermented milk in spontaneously hypertensive rats. Biosci. Biotechnol. Biochem. 58:776-778.

Zhang, A., H. Sun, S. Dou, W. Sun, X. Wu, P. Wang, and X. Wang. 2013. Metabolomics study on the hepatoprotective effect of scoparone using ultra-performance liquid chromatography/electrospray ionization quadruple time-of-flight mass spectrometry. Analyst 138:353-361.

Zhang, H., Y. Chen, W. Liu, Z. Sun, Q. Bao, and W. Zhang. 2012. Biological diversity of lactic acid bacteria in natural fermented dairy products. 1st ed. Science Press, Beijing, China. 